\title{
Identification of Canine Calicivirus Capsid Protein and Its Immunoreactivity in Western Blotting
}

\author{
Maria Concepcion S. SAN GABRIEL, Yukinobu TOHYA, Takaaki SUGIMURA, Tsutomu SHIMIZU1), Shinryo \\ ISHIGURO $^{2)}$, and Masami MOCHIZUKI ${ }^{3)}$ \\ Laboratories of Veterinary Microbiology and ${ }^{\prime \prime}$ Veterinary Pathology, Department of Veterinary Medicine, Faculty of Agriculture, \\ Kagoshima University, Kagoshima 890, and ${ }^{2}$ Tsukuba Central Laboratories and ${ }^{3}$ Laboratory of Clinical Microbiology, Kyoritsu Shoji \\ Co., Chiyoda-ku, Tokyo 102, Japan
}

(Received 7 October 1996/Accepted 28 October 1996)

ABSTRACT. A canine calicivirus (CaCV) isolated in Japan, designated as CaCV No. 48 strain, was propagated in MDCK cells and purified by $\mathrm{CsCl}$ equilibrium gradient centrifugation. Sodium dodecyl sulfate-polyacrylamide gel electrophoretic analysis of the purified samples revealed the presence of only one major species of viral protein of about 60 kilodaltons after Coomassie staining. The same band, presumably that of the capsid protein, was detected by western blotting using a mouse hyperimmune serum. This capsid protein was synthesized in MDCK cells as early as $2 \mathrm{hr}$ post-inoculation. Experimental infection of dogs resulted in the production of anti-CaCV antibodies which were detected by microneutralization test and western blotting. Likewise, serosurvey revealed not only the presence of neutralizing antibodies but also reactivity of the field sera against the capsid protein of the purified virus. These results indicate that the capsid protein of $\mathrm{CaCV}$ No. 48 strain is immunogenic and could be detected by antibodies in western blotting. - KEY wORDS: canine calicivirus, capsid protein, western blotting.

J. Vet. Med.Sci. 59(2): 97-101, 1997

The Caliciviridae is comprised of small, non-enveloped, positive-stranded RNA viruses characterized morphologically by cup-shaped depressions on the spherical capsid surface [4]. They affect a range of natural host species and are often associated with vesicular, respiratory and enteric infections [16]. The well-studied members of this group are vesicular exanthema of swine virus (VESV), San Miguel sealion virus (SMSV) and feline calicivirus (FCV). The recently recognized members include small round-structured viruses (SRSV) such as Norwalk virus $(\mathrm{NV})$ and Snow Mountain agent, hepatitis E virus and the rabbit hemorrhagic disease virus (RHDV) [4].

In dogs, a calicivirus was first isolated from a case of glossitis in 1979 [5]. Subsequently, more strains were identified in dogs with enteric infections [6]. These earlier isolates were found to be antigenically similar to FCV. In 1985, a calicivirus (CaCV) isolated from the feces of a dog with diarrhea was found to be not antigenically related to any previously described virus except to the stunting syndrome agent of chickens [13]. Two more isolates from cases of vesicular genital diseases were identified and based on neutralization tests, they appeared to be distinct from the previously reported canine and feline caliciviruses [3].

In our laboratory, two strains of caliciviruses were isolated from dogs with diarrhea. One is Sapporo/283 strain reported recently [12] and was found to be closely related to FCV antigenically. The other CPE-producing agent was isolated from a dog with fatal diarrhea and based on cell

* CoRRespondence to: Dr. TohyA, Y., Laboratory of Veterinary Microbiology, Department of Veterinary Medicine, Faculty of Agriculture, Kagoshima University, 21-24 Korimoto 1, Kagoshima 890, Japan. culture characteristics and biochemical and electron microscopic findings, it was classified as a calicivirus [9]. This isolate, designated as $\mathrm{CaCV}$ No. 48 strain had no antigenic relationship to $\mathrm{FCV}$ as determined by serum neutralization and complement fixation tests. Preliminary characterization of this strain was reported in the previous paper [9], however, further analysis is necessary to elucidate its features. Therefore, the objectives of the present study are to purify CaCV No. 48 strain, identify its capsid protein and determine its immunoreactivity in western blotting.

\section{MATERIALS AND METHODS}

Virus and cells: CaCV No. 48 strain was initially grown in Madin-Darby canine kidney (MDCK) cells as described previously [9]. Stock virus was prepared by inoculating MDCK cell suspension cultures. After freezing and thawing, the viral fluid was titrated and stored in aliquots at $-80^{\circ} \mathrm{C}$. MDCK growth medium consisted of Eagle's minimal essential medium (MEM) supplemented with $10 \%$ Tryptose phosphate broth and 5\% calf serum while the maintenance medium (MM) for propagating the virus was serum-free.

Virus propagation and purification: MDCK cells were grown either in $60 \mathrm{~mm}$ plastic dishes or in $690 \mathrm{~cm}^{2}$ roller bottles. The virus was allowed to adsorb for $1 \mathrm{hr}$ at $37^{\circ} \mathrm{C}$ and after removing the unadsorbed virus, MM was added. When CPE was maximal, usually after 2 days, the infective supernatant was clarified and layered onto a $25 \%$ sucrose cushion and centrifuged at 25,000 rpm for $2 \mathrm{hr}$ (Hitachi SRP28SA). The pellet was then resuspended in phosphatebuffered saline (PBS) and centrifuged to remove insoluble matter. The concentrated samples were then pooled and 
$\mathrm{CsCl}$ crystals were added to each tube to adjust the density to $1.38 \mathrm{~g} / \mathrm{ml}$. The solution was then ultracentrifuged at $46,000 \mathrm{rpm}$ for at least $16 \mathrm{hr}$ (Hitachi RPS50-2). Fractions of about $0.2 \mathrm{~m} l$ were collected through a puncture at the bottom of the tube and were assayed for viral infectivity and for determination of buoyant density.

Microtitration: The fractions were first diluted 100 times to reduce the cytotoxic effect of $\mathrm{CsCl}$ and then 10-fold dilutions were done in MEM with $5 \%$ FCS. Fifty $\mu l$ of each dilution were dispensed in the wells of a 96-well flatbottomed polystyrene plate and $50 \mu l$ of $4 \times 10^{5} / \mathrm{m} l$ MDCK cells were then added to each well. The plates were incubated at $37^{\circ} \mathrm{C}$ for $72 \mathrm{hr}$ and the $\mathrm{TCID}_{50} / 50 \mu l$ was calculated.

Sodium dodecyl sulfate-polyacrylamide gel electrophoresis (SDS-PAGE) and western blot analysis: Fractions containing high infective titers were pooled and dialyzed against 1,000 volumes of PBS overnight. An equal volume of $2 \times$ SDS loading buffer ( $0.1 \mathrm{M}$ Tris- $\mathrm{Cl} \mathrm{pH} 6.8$, $0.2 \mathrm{M}$ dithiothreitol, $4 \%$ SDS, $0.2 \%$ bromophenol blue and $20 \%$ glycerol) was added to the purified samples and 15 to $20 \mu l$ were loaded onto a $10 \%$ acrylamide gel and electrophoresed for about $3 \mathrm{hr}$ at 80 volts. After the run, the proteins were either stained with Coomassie brilliant blue or transferred to a polyvinylidene difluoride filter (Millipore, U.S.A.) overnight at 15 volts using a transblot apparatus (Bio Rad, U.S.A.). The blots were first incubated with the appropriate sera and then reacted with peroxidase conjugate. The bands were visualized after addition of the tetramethylbenzidine substrate from a commercial kit (Kirkegaard \& Perry Laboratories, U.S.A.).

Production of mouse hyperimmune sera: Four-week-old mice were inoculated intraperitoneally with ammonium sulfate-precipitated virus mixed equally with complete Freund's adjuvant. Additional injections without adjuvant were given every three weeks and test bleeds were done to monitor the immune response. Once a satisfactory neutralizing titer was achieved, the mice were sacrificed and blood was collected. Microneutralization test (MNT) was performed to titrate the serum samples.

Microneutralization test: This assay was performed essentially according to the method described previously [11]. Briefly, after inactivation at $56^{\circ} \mathrm{C}$ for $30 \mathrm{~min}$, serum samples were diluted 2-fold or 10-fold in MEM with 5\% FCS. Twenty-five $\mu l$ of each diluted sample was dispensed in each well of a 96-well plate. Challenge virus in $25 \mu \mathrm{l}$ was then added to each well to deliver a dose of $100 \mathrm{TCID}_{50}$. Serum control wells without virus were also included to determine the cytotoxicity. After $1 \mathrm{hr}$ incubation at $37^{\circ} \mathrm{C}$ with occasional shaking, $50 \mu l$ of MDCK cells $\left(4 \times 10^{5}\right.$ cells $/ \mathrm{m} l$ ) were added. The plates were then observed for 48 to $72 \mathrm{hr}$.

Time course of capsid protein synthesis: Confluent MDCK monolayer cells were infected with the virus at an m.o.i. of 0.1 . After adsorption for $1 \mathrm{hr}$ at $37^{\circ} \mathrm{C}$, infected and mock-infected cell lysates were collected at $0,1,2,3$, 4 , and $5 \mathrm{hr}$ post-inoculation (PI) and processed for western blot analysis. The membrane was probed by a mouse hyperimmune serum diluted 1:500 to detect the capsid protein.

Experimental dog infection: Four specific-pathogen-free 7-month-old beagle puppies with low neutralizing antibody (1:2) were used for experimental infection. Two (dog Nos. 61 and 62 ) were given $10^{5.6} \mathrm{TCID}_{50} / 20 \mathrm{~m} l$ orally while the other two (dog Nos. 63 and 64) received $10^{5.3} \mathrm{TCID}_{50} / 10 \mathrm{ml}$ intravenously. Blood samples were collected at $0,3,6,9$, $12,15,18,21,24,27$ and 30 days PI. The samples were tested for neutralizing activity as well as immunoreactivity in western blotting.

Dog field serum samples: A total of 58 field samples were collected from 1981 to 1991 in Kagoshima area. After inactivation at $56^{\circ} \mathrm{C}$, the serum samples were assayed for the presence of anti-CaCV neutralizing antibodies by MNT and were also reacted against the capsid protein of the purified virus in western blotting (serum dilution, 1:20).

\section{RESULTS}

1. Virus propagation and purification: By using monolayer MDCK cells grown either in $60 \mathrm{~mm}$ dishes or roller culture bottles, virus yields with titers ranging from $10^{3}$ to $10^{5} \mathrm{TCID}_{50} / 50 \mu l$ could be harvested after 36 to $48 \mathrm{hr}$ PI. Sucrose cushion centrifugation resulted in a 10 to a 100 -fold increase in the virus titers. Titration of the $\mathrm{CsCl}$ fractions revealed the presence of a viral peak with a buoyant density ranging from 1.36 to $1.38 \mathrm{~g} / \mathrm{ml}$ (Fig. 1).

2. SDS-PAGE analysis: The protein bands from virusinfected and mock-infected samples were separated in a $10 \%$ polyacrylamide gel and stained with Coomassie brilliant blue (Fig. 2). After sucrose cushion centrifugation, several bands

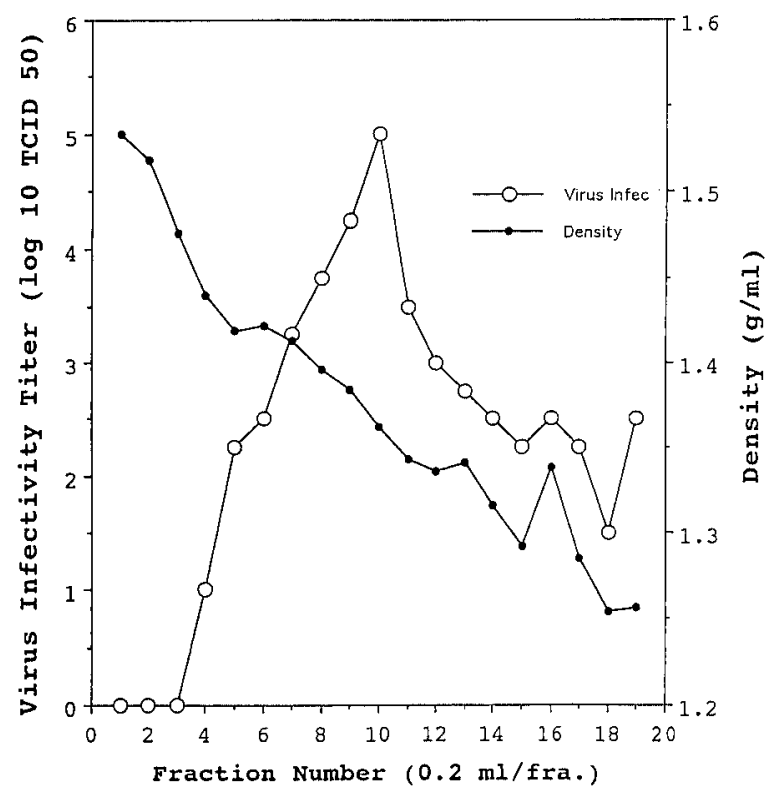

Fig. 1. Infectivity assay and buoyant density measurements of CsCl-purified CaCV No. 48 strain fractions. 


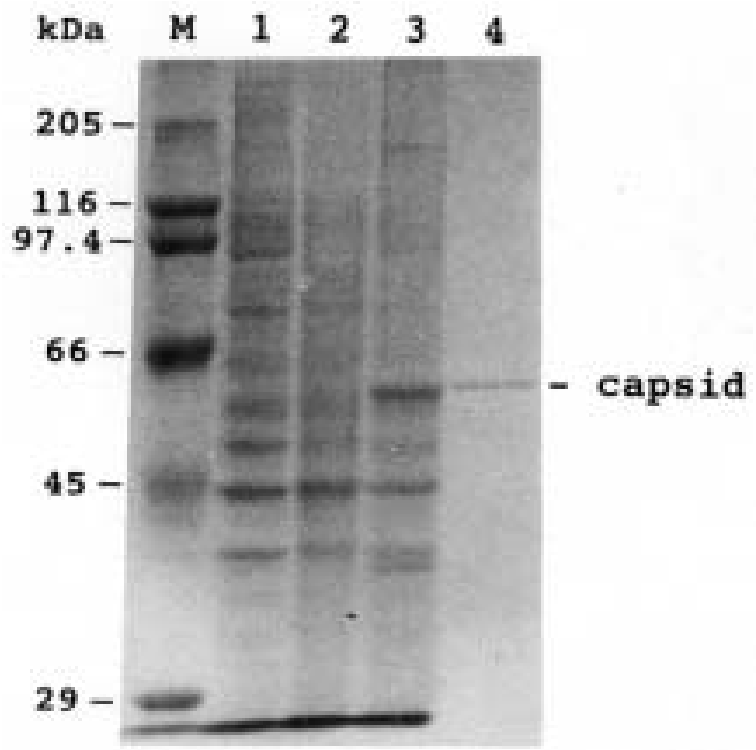

Fig. 2. SDS-PAGE analysis of CaCV No. 48 strain. Lanes: M, molecular weight markers; 1 , mock-infected cell lysates; 2 , virus-infected cell lysates; 3 , infective supernatant after sucrose cushion centrifugation; $4, \mathrm{CsCl}$ purified sample.

indicating cellular debris contamination were still apparent but a distinct band of about 60 kilodaltons (kDa), presumably that of the capsid protein, was already visible (Fig. 2, lane 3). After $\mathrm{CsCl}$ purification, most of the cellular contaminants were eliminated and only a major band of 60 kDa was observed (Fig. 2, lane 4).

3. Time course of capsid protein synthesis: At $2 \mathrm{hr}$ PI, CPE characterized by a few cells rounding up was already apparent and a very faint band of about $60 \mathrm{kDa}$ could be observed after western blotting (Fig. 3, lane 2). As CPE became more progressive, the intensity of the band also increased until the end of the collection period (Fig, 3, lanes 3, 4 and 5).

4. Experimental infection: Experimentally inoculated dogs exhibited no apparent clinical symptoms such as diarrhea and vomiting but they produced increasing titers of neutralizing antibodies against $\mathrm{CaCV}$ No. 48 strain. However, the immune response detected by MNT differed to some extent among the dogs (Fig. 4). The titers peaked by the 12th day (except in one dog) and two dogs had neutralizing titer of 1:256. Likewise, there was difference in the western blot patterns among the dogs. The capsid protein could be detected as early as 3 days PI in one dog (No. 63) and until 30 days PI in all dogs. Some blots also showed an increasing intensity of the band suggesting a parallel increase in the production of western blot immunoreactive antibodies (data not shown).

5. Serosurvey of dog field samples: Results of the MNT of the dog field samples revealed the presence of anti-CaCV neutralizing antibodies with titers ranging from 1:8 to $1: 640$ in $82.7 \%$ of the samples tested. Moreover, 5 out of 15 selected sera with neutralizing titers from $1: 160$ to $1: 640$

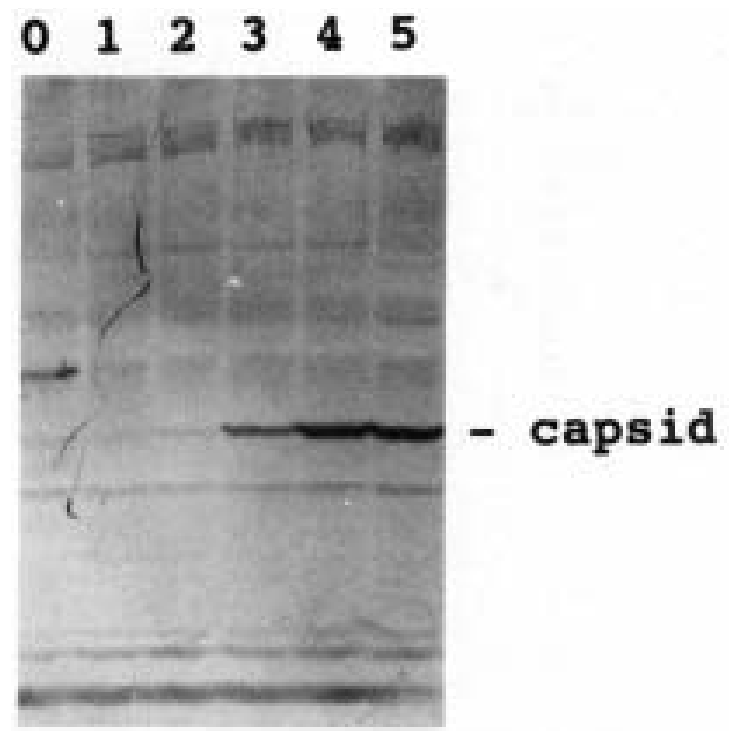

Fig. 3. Western blot analysis of capsid protein synthesis of CaCV No. 48 strain. Lanes: $0,0 \mathrm{hr}$ post-inoculation (PI); 1, 1 hr PI; 2, 2 hr PI; 3, 3 hr PI; 4, 4 hr PI; 5, 5 hr PI.

reacted against the purified virus after western blotting (data not shown).

\section{DISCUSSION}

There are only a few canine calicivirus strains reported so far unlike the other prototype animal caliciviruses which could be easily isolated in cell cultures. CaCV No. 48 strain is one of only two caliciviruses isolated from dogs in Japan [9, 12]. It could produce CPE in MDCK cells, however, several difficulties were encountered in producing high-titered viral preparation for purification purposes. The virus apparently replicated more efficiently in semiconfluent monolayer cells than in full sheets. Schaffer et al. [13] observed that the early passaged virus required freshly plated or rapidly dividing cells. Furthermore, in contrast to $\mathrm{FCV}$, it was not possible to obtain virus titers of more than $10^{7} \mathrm{TCID}_{50} / \mathrm{m} l$ in MDCK cells. Virus entry and replication are probably influenced by factors associated with the cells or the culture medium. Therefore, future studies are focused on improving cell culture conditions to increase virus yield or finding more permissive cell lines.

$\mathrm{CsCl}$ equilibrium gradient centrifugation had been used successfully for purification of other caliciviruses [10, 17]. Likewise, it was a satisfactory method for purifying $\mathrm{CaCV}$ No. 48 strain resulting in detection of only one major protein band of about $60 \mathrm{kDa}$ after Coomassie staining. This finding further confirms that the strain belongs to Caliciviridae since members of this family possess a capsid composed of only one major species of polypeptide [4]. The apparent molecular weight of the capsid protein of CaCV No. 48 strain was similar to that of the $\mathrm{CaCV}$ described by Schaffer 

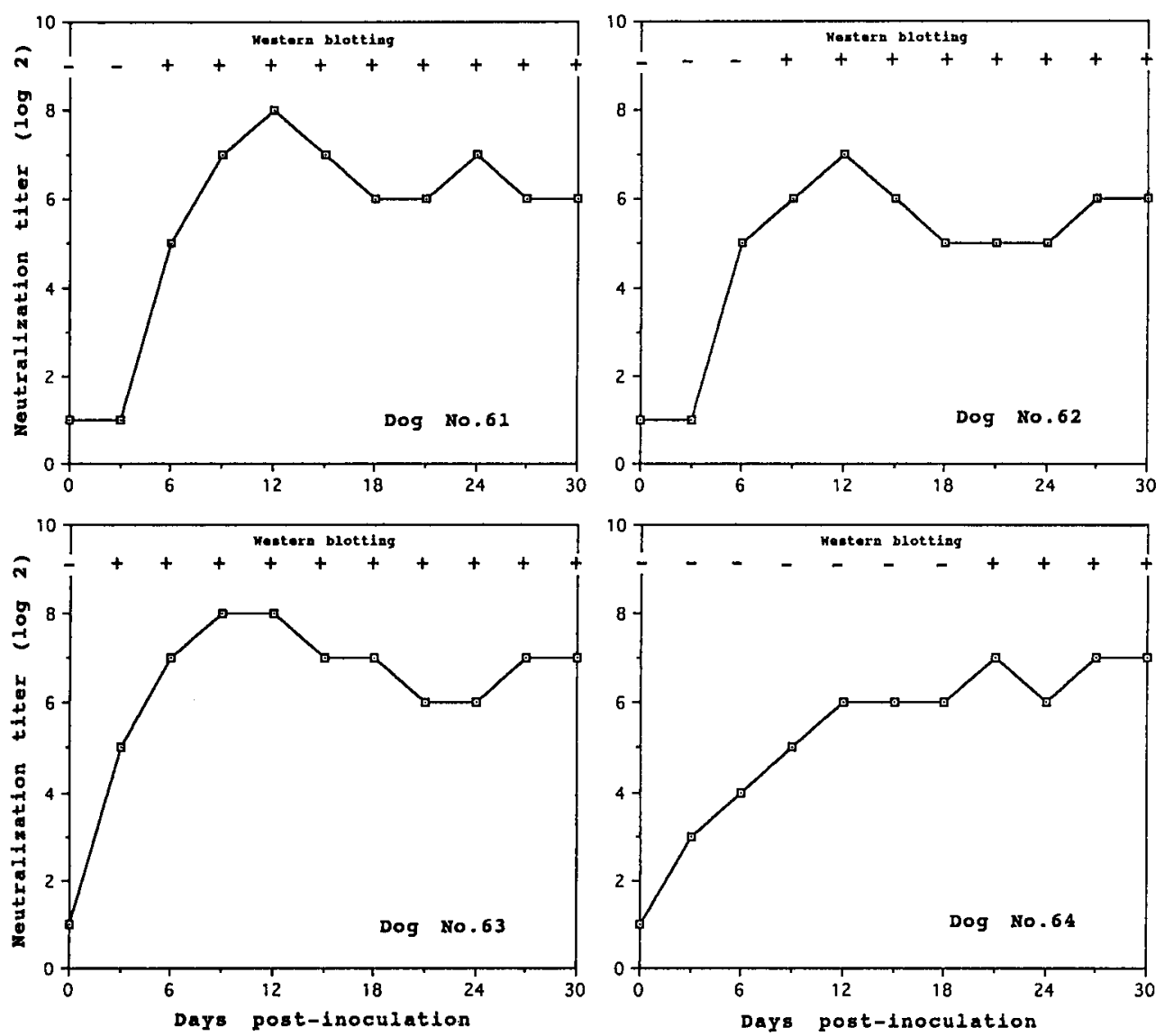

Fig. 4. Neutralizing antibody titers and western blot results of experimentally infected dog serum samples. + indicates the detection of the capsid protein in western blotting (serum dilution, 1:20).

et al. [13], RHDV [10] and NV [7] but slightly less than that reported for FCV $[1,15,18]$.

The time course study of capsid protein synthesis revealed that the protein band was already detectable by the mouse serum at $2 \mathrm{hr}$ PI. Carter [2] carried out a similar experiment using FCV strain F9 and reported the detection of the FCV capsid protein by a cat serum as early as $1 \mathrm{hr}$ PI. Several non-structural virus-specific bands were also detected by the cat serum. We attempted to use sera from the experimentally infected dogs but unlike the mouse hyperimmune serum, they were unable to detect the low amount of capsid protein produced at 2 and $3 \mathrm{hr}$ PI. Furthermore, the sera reacted with other extraneous proteins present in virus-infected and mock-infected preparations thereby making it difficult to identify viral specific bands.

Attempts had been made to reproduce the original disease by experimentally infecting puppies with $\mathrm{CaCV}[9,13]$. In this study, the puppies were inoculated orally or intravenously and the immune response was monitored by MNT and western blotting to confirm the presence of antibodies reactive in western blot and the immunogenicity of the capsid protein. The anti-CaCV antibodies were detected by both tests, although the capsid protein could only be detected when the sera had a neutralizing titer of at least 1:32.

Analysis of serum samples collected from Kagoshima area revealed the prevalence of anti-CaCV neutralizing antibodies indicating that canine caliciviruses similar to CaCV No. 48 strain are probably widespread in the dog population. However, many of the high-titered neutralizing sera were not reactive in the western blot suggesting that most of the neutralizing epitopes were probably destroyed upon denaturation of the protein during western blotting. MNT appears to be a more sensitive test than western blotting in detecting antibodies. However, western blotting had been used to examine porcine sera for detection of SMSV and VESV antibodies as well as determine crossreactivity among SMSV and VESV strains [14]. Furthermore, it had also been used for detecting antibodies against SRSV [8]. Therefore, it would be a potential tool for the seroepidemiology of calicivirus infection.

ACKNOWLEDGMENTS. The authors would like to thank Mr. Jinjun Li for assisting in the preparation of the figures. Ms. M. C. San Gabriel is receiving a scholarship from the Ministry of Education, Science, Sports and Culture of Japan. 


\section{REFERENCES}

1. Carter, M. J., Routledge, E. G., and Toms, G. L. 1989. Monoclonal antibodies to feline calicivirus. J. Gen. Virol. 70: 2197-2200.

2. Carter, M. J. 1989. Feline calicivirus protein synthesis investigated by western blotting. Arch. Virol. 108: 69-79.

3. Crandell, R. A. 1988. Isolation and characterization of caliciviruses from dogs with vesicular genital disease. Arch. Virol. 98: 65-71.

4. Cubitt, D., Bradley, D. W., Carter, M. J., Chiba, S., Estes, M. K., Saif, L. J., Schaffer, F. L., Smith, A. W., Studdert, M. J., and Thiel, H. J. 1995. Family Caliciviridae. pp. 359-363. In: Virus Taxonomy (Murphy, F. A., Fauguet, C. M., Bishop, D. H. L., Ghabrial, S. A., Jarvis, A. W., Martelli, G. P., Mayo, M. A., and Summers, M. D. eds.), Springer-Verlag, Wien.

5. Evermann, J. F., Bryan, G. M., and McKeirnan, A. J. 1981. Isolation of a calicivirus from a case of canine glossitis. Canine Prac. 8: 36-39.

6. Evermann, J. F., McKeirnan, A. J., Smith, A. W., Skilling, D. E., and Ott, R. L. 1985. Isolation and identification of caliciviruses from dogs with enteric infections. Am. J. Vet. Res. 46: 218-220.

7. Greenberg, H. B., Valdesuso, J. R., Kalica, A. R., Wyatt, R. G., McAuliffe, V. J., Kapikian, A. Z., and Chanock, R. M. 1981. Proteins of Norwalk virus. J. Virol. 37: 994-999.

8. Hayashi, Y., Ando, T., Utagawa, E., Sekine, S., Okada, S., Yabuuchi, K., Miki, T., and Ohashi, M. 1989. Western blot (immunoblot) assay of small, round-structured virus associated with an acute gastroenteritis outbreak in Tokyo. J. Clin. Microbiol. 27: 1728-1733.

9. Mochizuki, M., Kawanishi, A., Sakamoto, H., Tashiro, S.,
Fujimoto, R., and Ohwaki, M. 1993. A calicivirus isolated from a dog with fatal diarrhoea. Vet. Rec. 132: 221-222.

10. Parra, F. and Prieto, M. 1990. Purification and characterization of a calicivirus as the causative agent of a lethal hemmorrhagic disease in rabbits. J. Virol. 64: 4013-4015.

11. Povey, R. C. 1974. Serological relationships among feline caliciviruses. Infect. Immun. 10: 1307-1314.

12. San Gabriel, M. C., Tohya, Y., and Mochizuki, M. 1996. Isolation of a calicivirus antigenically related to feline caliciviruses from feces of a dog with diarrhea. J. Vet. Med. Sci. 58: 1041-1043.

13. Schaffer, F. L., Soergel, M. E., Black, J. W., Skilling, D. E., Smith, A. W., and Cubitt, W. D. 1985. Characterization of a new calicivirus isolated from feces of a dog. Arch. Virol. 84: 181-195.

14. Seal, B. S., House, J. A., Whetstone, C. A., and Neill, J. D. 1995. Analysis of the serologic relationship among San Miguel sea lion virus and vesicular exanthema of swine virus isolates. Application of the western blot assay for detection of antibodies in swine sera to these virus types. J. Vet. Diagn. Invest. 7: 190-195.

15. Seal, B. S., Ridpath, J. F., and Mengeling, W. L. 1993. Analysis of feline calicivirus capsid protein genes: identification of variable antigenic determinant regions of the protein. J. Gen. Virol. 74: 2519-2524.

16. Studdert, M. J. 1978. Caliciviruses. Arch. Virol. 58: 157-191.

17. Terashima, H., Chiba, S., Sakuma, Y., Kogasaka, R., Nakata, S., Minami, R., Horino, K., and Nakao, T. 1983. The polypeptide of a human calicivirus. Arch. Virol. 78: 1-7.

18. Tohya, Y., Masuoka, K., Takahashi, E., and Mikami, T. 1991. Neutralizing epitopes of feline calicivirus. Arch. Virol. 117: 173-181. 